\title{
The Impact of Internal Communication in Organizational Management
}

\author{
Maria Daniela Pipaş ${ }^{1}$, Camelia Lucia Bakri \\ ${ }^{I}$ Associate Professor, Ph.D., Faculty of Economics, Management-Finance-Accounting Department, "Bogdan Vodă", \\ University of Cluj-Napoca,Cluj-Napoca,Romania,dpipas@yahoo.com \\ ${ }^{2}$ Primary Physician of Family Medicine, Ph.D, ,, Sanor”, Medical Center of Cluj-Napoca, Cluj, Romania, \\ camelia_bakri@yahoo.com
}

\begin{abstract}
Modern society represents a set of organizations. Almost all aspects of human existence are regulated, assisted or facilitated by an organization or another. Almost all people are part of the structures and processes of a type of organization, be it family, school, government, church, business or club. According to a simple definition, an organization is the combination and use of human, financial and material resources to achieve objectives. The organization is a social system composed of activities that brings together human and material resources, through which the objective for which it was created is achieved: products, works, services appropriate to social order. The organization is not defined only by its products and/or services, but also by the manager's ability to communicate with employees and the management team. All activities related to the organization are mediated by communication, so communication is a key element in the organizational processes, interfering with their success or failure. Communication is one of the most important organizational activities. Fundamentally, human relations grow out of communication and the functioning and survival of organizations is based on effective relationships between individuals and groups. Moreover, organizational capabilities are adopted and developed through intense social and communication processes. Internal communication, seen as a set of procedures and organized communication exchanges, participates in the construction of numerous definitions of problematic situations underlying the understanding and behavior of employees. Every organization has its moments of glory and decay in functional and communicative terms. It is very easy to go from an effective communication situation to a poor one, given the multitude of factors that can disrupt the flow of information and communication of a group or of an organization. Like any activity that takes place within the organization, communication must have a planned dimension; it cannot be done randomly, but requires a plan, a strategy, rules and procedures. In other words, communication must be institutionalized and incorporated into the strategic plan of the organization. Communication is specific to each organization; each organization has its own communication system based on the profile, size and especially the organizational culture.
\end{abstract}

KEYWORDS: internal communication, management, managers, efficiency, organization

\section{Introduction}

Trying to find a universally valid definition for communication is almost impossible. Most communication specialists have suggested definitions, more or less comprehensive for this term. Any explanatory dictionary speaks of notice, information, knowledge, update, etc.

From the sociological point of view, communication is a fundamental psychosocial interaction of people, achieved through articulated language or codes in order to send a message, with the purpose of modifying individual or group behavior.

Communication, unlike other components of management and organization as a whole, has features that prevent its research in the same way as other organizational or managerial problems. First, communication is pervasive in all company activities; its study cannot be done in isolation, but in an organizational context by integrating managerial functions.

In this context, we can state that the organization is a social system of activity that brings together human and material resources through which the goal for which it was created is realized: products, works, services, corresponding to the social order.

The structure results from the combination or relationship of people, groups and leaders. Each of the three categories of elements is an important subsystem of the organization - the individual subsystem, the group subsystem and the management subsystem. The individual subsystem is 
dominated by characteristic processes such as communication, adaptation, motivation and development (professional and human evolution).

As organizations grow they are dealing with a number of key aspects of organizational management, namely human resource management. Managers create a plan to attract and retain people with the skills needed by the organization. Implementing the plan involves the recruitment, selection, integration, training, rewarding, choosing the most appropriate benefits and ongoing assessment of performance to verify whether organizational objectives are achieved.

By management as a science we understand: "the study of management processes and relationships within the organizations in order to discover legalities and principles that govern them and designing new systems, methods, techniques of management, such as ensuring acquisition and competitiveness" (Nicolescu \& Verboncu 2008, 38).

Organizational management is a series of activities (functions) including planning (forecasting), organization, guiding (coordination) with decision-making, training and control of the assessment, all geared to the use of human, financial, material and information resources of an organization in a effective and efficient manner necessary to achieve organizational objectives. Consequently, the five functions are vital for a real, effective and efficient management. The interdependence of management functions is shown in Figure no. 1.

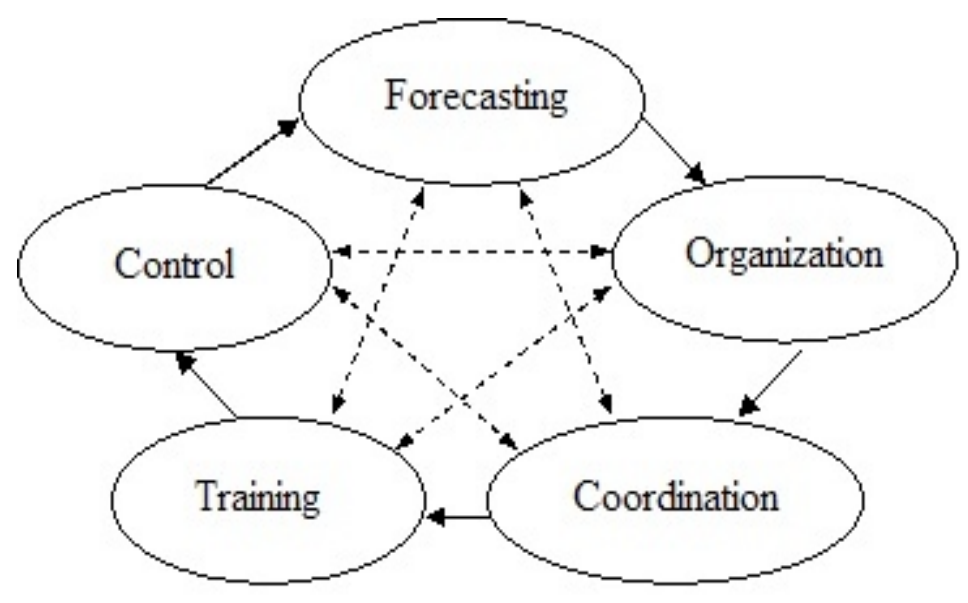

Figure no. 1 - Interdependence between management functions

Source: Nicolescu \& Verboncu 2008, 49

The interdependent approach to management functions is determined by the systemic nature of the organization being closely related to organizational communication. A management review is related, in principle, to the ways of approach, namely, the complexity and content of activities when exercising organizational approach. From the types of management analysis we can list: causal approach, empirical, behavior and interpersonal communication, group behavior and communication, system of cooperation, decision theory, system approach, the mathematical approach (mathematical, computerized management), situational approach (tangents), addressing the role of management, operational approach. Since all these approaches are evidenced by effective communication we must take into account the importance of organizational communication.

\section{A brief foray into theories of organizational communication}

The study of organizational communication concerns researchers and practitioners interested in the welfare of the organization. Since classical theories and going all the way to the modern ones, there was hardly any thinker which does not relate in one way or another to the role of organizational communication. 
For Frederick Taylor, a great importance was held by the hierarchical communication plan while for Hanry Fayol horizontal communication conducted between people on the same hierarchical level but belonging to different hierarchical lines was essential. If for both of them the communication between bosses and subordinates was essential, for the representatives of the current of human relations and resource (Mayo, McGregor, Likert) the most important are communication relationships within the group. This opens the way to study the informal communication quite neglected previously.

Modern theories bring with them an integrative perspective in the study of communication, which is extended to the entire organization. It acknowledges the role of external and environmental factors and the need to correlate different phenomena such as social or psychological ones.

Traditionally, communication has been seen as a linear process comprising a transmitter that sends a message to a receiver, message that is understood, internalized and on which the receiver acts. Research in organizational communication has focused on how this process can be conducted in order to improve performance, productivity and profitability.

The modern management emphasizes further the role of communication in business management. Thus, it is considered that the managers spend between around 60 and $80 \%$ of the time communicating (Luthans \& Larsen 1986. apud. Hargie Tourish 2009, 22). Studies show that effective managers spend a great deal of time in activities based on communication. Even from 1973 Mintzberg revealed the ubiquitous nature of interpersonal communication in management activities (Mintzberg 1973, 18).

More recent studies of leadership reaffirm that effective leadership at the work place involves the constant use of communication tools in order to create meaning, to share views and to build a common purpose (Sims \& Lorenzi 1992 apud Hargie \& Tourish 2009, 25).

Organizational efficiency and effectiveness depend heavily on the managers' ability to send messages within and outside the organization with maximum efficiency. The human ability means the ability to work well in collaboration with others. At work, human skills are manifested in the form of enthusiasm, confidence, and real involvement in interpersonal relationships. In this regard, we identified certain skills and abilities that contribute to the effective organizational communication process. After Jennifer M. George \& Gareth R. Jones (George \& Jones 2011, 53), in the instance of emitters, managers should possess certain skills while in the position of recipients of messages they should possess a different set of skills, as described in Table 1.

Table 1. Skills required of managers in their role as transmitters/receivers of them messages

Managerial skills of managers in their capacity as transmitters of messages

- To encode the message into symbols that the receiver can understand;

- To send messages that are clear and complete;

- To avoid the filtering and distortion of information;

- To ensure that the feedback mechanism is embedded in the message;

- To provide accurate information to ensure that misleading rumors don't spread.

Managerial skills of managers in their capacity as receivers of messages

- To be careful (managers, busy as they are, should pay attention to all the messages they receive);

- To be good listeners (to refrain from interrupting others, maintain eye contact, to ask questions to clarify items after receiving the message, to paraphrase or rephrase important points as a form of feedback);

- To show empathy;

- To understand linguistic styles through the awareness of cultural differences. 
Nowadays, communication is widely recognized as "the key to organizational excellence and effectiveness" (Gruning 1992).

Philippe Cabin, said: "Currently, the communication within the organization is a less structured research area, divided into very different approaches: interpersonal communication, group dynamics, sociology of organizations, management, semiotics, sociolinguistics ... Very recent studies tend to provide a pluralist and systemic analysis of phenomena related to communication in the organization" (Cabin \& Dortier coord. 2010, 147).

No matter how strong an organization is, it cannot function properly without a good system of communication. Communication is what keeps the organization together and makes it work. The effectiveness of communication is vital to the effectiveness of the entire organization.

Like any activity that takes place within the organization, communication too must have a planned size; it cannot be done at random, but needs a plan, a strategy, rules and procedures. In other words, communication must be institutionalized and incorporated into the strategic plan of the company.

\section{Management and communication}

Management has always been linked to communication. Like people, organizations have their own destiny, and its search and fulfillment differentiates a performing organization from an underperforming one. Managers are those who have a special responsibility for the mission and can perform it through a deep understanding of the past, mature approach on the present and by creating a "picture" of the future. The organization is not defined only by its products and / or services, but also through the manager's ability to communicate to its employees and the management team.

Broadly, the manager is the person applying management functions in line with the tasks, powers and responsibilities assigned to the position they perform.

The manager will always use communication processes to be understood in order to coordinate its business activities and to make decisions and implement them, in order to enter into partnership and collaborations etc. "Communication is, in terms of management, the process by which people are informed and advised to get the best results. Communicating effectively is not only to put your thoughts in order and present them in an accessible way, but also to express them in a way that will capture the attention of the receiver" (Keenan 2002, 59).

The manager must consider including the individual's emotional side and paying attention to each receiver when transmitting the message because "for management, information is conditio sine qua non. The same can be said about the inner communication of any organization, given that within the organization, information must reach the court (person or group) when appropriate and necessary. Otherwise the information loses its value". (VanCuilenburg and Scholten Noomen 1998, 98). Schematically, the share of managers' activities - in the conceptual dimension, of human relations (motivation, training, communication) and the technical level is different depending on each operating level.

Managers work their obligations deriving from the functions of management: create and implement development strategies, make predictions and plans; organize and coordinate the work; provides a favorable climate for performance, that motivates employees; is working to raise the efficiency of leadership; promotes the communication with the staff, with customers and suppliers; develops strategic relationships etc.

Managers are associated to action verbs: to do, to develop, to intervene, to direct, to correct and the like. Managers do not maintain steady but dynamic phenomena; they do not seek an existing situation, if it is no longer profitable. Managers are often associated to the verb to change. Their characteristic is that they can identify the true hierarchy of priorities, that they can operate effectively in interdisciplinary areas with a high degree of uncertainty, taking risks and finding ways to solve, not least through the joint efforts of their employees. (Stanciu, Ionescu, Leovaridis and Stanescu 2003, 59).

Credibility is hard to gain in an environment where information flows are both formal and informal. The audience will always listen to what the boss has to say, but the latter cannot be sure if 
he was pursued to the end and believed: "If the listeners do not infer from what you say or how you say something, that you're credible, you have little chance to be followed to the end. It is clear that when people do not listen or pay attention to things that are communicated to them, they will remember only a small part of them. And from there to complement the message in error is only one step" ( Keenan 2002, 9).

Organizations have always satisfied their communication requirements. But this does not mean that they followed a strategic approach to communication management. To illustrate the previous statement we stop at the models proposed by Ulrich (Ulrich 1970) and Bleicher (Bleicher 1999).

Ulrich uses four managerial dimensions: physical, social, value and communicative. Bleicher describes the need for communicating the policies, organizational and cultural rules of the firms. Both authors see communication rather as a tool with a facilitating role rather than as one of the actions involved in development or management itself.

In this respect, Alex Mucchielli (Mucchielli 2008, 254) defines internal communication as: " $a$ mix of communication exchanges developed by the managers involved in the situation. This communication plan aims to address the main issues arising in the situation defined at the beginning by the organization's management, providing as much as possible, a response built by actors directly involved." In his organization, the manager will permanently have to resolve issues. Thus, at any level of management he would be, he will have to solve problems related to work organization, organizational aspects, coordination, decision-making and not least, he will have to solve issues related to the evolution and change in the organization.

"Management appears to us as the art to solve, through various forms of internal communication, the standard and recurring organizational problems faced by every manager. This definition is essential, because it allows, through the manager's position, to catalog the internal communication as a management tool" (Mucchielli 2008, 259).

The systematic and constructivist model of communication considers communication as a response of the actors to the problems and situations in the organization. Internal communication results thus as a building together of people within the organization.

Internal communication is a managerial act because it is initiated and coordinated by the management and because it responds to an issue that reveals the functioning of the organization and its human potential.

Through internal communication, communication and information sciences become partners of management sciences. This finding entitles us to say that in an efficient organization, internal communication is undoubtedly a participatory management tool that gives employees the opportunity to express their opinions by turning them into involved, competent and inventive partners in solving the problems which they face.

The increased frequency and amplitude of the organizational communication is one of the factors that can ensure increased job satisfaction, loyalty and motivation. The absence of communication or random communication is a sign of poor and counterproductive management.

If managers do not perceive the structural and functional imbalances, if they do not encourage the development of group relations and communication, if the organization does not practice human resource performance policies and the like, the staff will engage increasingly less in work and there will be conflicts of work and also truancy and dropout.

\section{Conclusions}

Managers are supposed to have an overview of all the opportunities that increase employee productivity. Such an opportunity is also the use of effective managerial communication to increase this indicator.

Effective communication is the key to the success of a modern organization. Within the organization, it strengthens employees' trust in the vision and mission of the organization, connects employees to the reality of the business, achieves goals, strengthens the organization's development process, facilitates changes necessary to progress, and contributes to changing employee behavior. 
On the outside, the image of the organization, the discovery of new business opportunities and the relationship with society depend to a large extent on how well this continuous process of communication is conceived and guided.

Organizational efficiency and effectiveness depend heavily on the managers' ability to send messages within and outside the organization with maximum efficiency. No matter how strong an organization is, it cannot function properly without a good system of communication. Communication is what keeps the company together and makes it work. The effectiveness of communication is vital to the effectiveness of the entire organization.

Communication plays an important role in evaluating and motivating the human resource. If a manager does not close the loop and regularly communicate with employees, he will not be able to understand their needs and to assess the performance correctly. Moreover, an excessive severity and criticism creates a stressful atmosphere within the organization and employees will begin to reject the communication out of fear or as a precaution. The lack of communication between management and employees may result in poor performance and even conflicts.

Through internal communication, the science of communication and information become partners of the management sciences. This finding enables us to say that in an effective organization, the internal communication is undeniably a participatory management tool, which gives employees the opportunity to express their views turning them into involved partners, competent and resourceful in solving the problems they face.

\section{References}

Bleicher, Knut. 1999. Das Konzept Integriertes Management: Visionen - Missionen - Programme. $5^{\text {th }}$ Edition, rev and enl. Frankfurt.

Cabin, Philippe, Dortier Jean-François (coord.). 2010. Communication. Iaşi: Polirom Publishing House.

George, Jennifer M. \& Jones Gareth R. 2011. Understanding and Managing Organizational Behavior. Student Value Edition. 6th Edition. Pearson Publishing House.

Grunig, James E. 1992. Excellence in Public Relations and Communication Management. London: Routledge.

Keenan, Kate. 2002. Efficient manager guide, how to communicate. Translation of Antoaneta Paraschiv. Bucharest. Rentrop\&Straton. Publishing and Business Advice Group.

Luthans \& Larsen. 1986. apud. Hargie, O. \& Tourish, D. Auditing Organizational Communication. New York: Taylor \& Francis. 2009.

Mintzberg, Henry. 1973. The Nature of Managerial Work. New York: Harper \& Row Publishing House.

Mucchielli, Alex. 2008. Communication in institutions and organizations. Iaşi: Polirom Publishing House.

Nicolescu, Ovidiu, Verboncu Ion. 2008. Fundamentals of organization management. Bucharest. Universitaria Publishing House.

Sims \& Lorenzi.1992. apud. Hargie \& Tourish. Auditing Organizational Communication. New York: Taylor\& Francis. 2009.

Stanciu, Ştefan, Ionescu Mihaela, Leovaridis Cristina, and Stanescu Dan. 2003. Human resources management. Bucharest: Publisher Comunicare.ro.

Ulrich, Hans G. 1970. Die Unternehmung als produktives, soziales System: Grundlagen der allgemeinen Unternehmungslehre. $2^{\text {nd }}$ edition. Bern.

VanCuilenburg, J.J., Scholten O., and Noomen G.W. 1998. Communication Science. Romanian version and introductory study, Tudor Olteanu. Bucharest: Humanitas Publishing House. 